Psychology of Language and Communication 2012, Vol. 16, No. 2

VERSITAOPEN

DOI: 10.2478/v10057-012-0011-y

\author{
PAWEŁ BOSKI ${ }^{1}$, KATARZYNA IBEN YOUSSEF ${ }^{2}$ \\ ${ }^{1}$ Polish Academy of Sciences \\ ${ }^{2}$ Warsaw School of Social Sciences and Humanities
}

\title{
CONSEQUENCES OF LINGUISTIC FRAME SWITCHING: COGNITIVE AND MOTIVATIONAL SHIFTS IN BILINGUAL TUNISIANS
}

\begin{abstract}
Bilingualism and biculturalism are of growing importance in the world today and of increasing research interest in social sciences. Since the seminal paper by Hong et al. (2000), researchers have explored cognitive consequences of cultural and/or linguistic frame switching on cognitive functioning, mainly causal attributions (Benet-Martinez et al., 2002). It was repeatedly found that when primed by either Chinese or Americans symbols, bicultural Chinese-Americans would act as monoculturals on each side of their hyphenated identity. Paradoxical effects of conflicting bicultural identity were also reported (Benet-Martinez, Haritatos 2005). Boski (2008) extended the arguments built on a particular cultural mix of Chinese-Americans category and the analytic - holistic cognitive divide, to other groups and to axiological domains among Polish-Americans. In the current study, bilingual Tunisians of two generations were asked questions pertaining to values entrenched in their immediate cultural milieu and about those reflecting their personal convictions. Also, they answered questions about their readiness to act according to extrinsic and intrinsic motivations, as well as about conflicts between these two tendencies. Language (Arabic vs. French) was the key contrasting variable in our study. The findings clearly demonstrated that when using the French language, participants of both generations became not only less extrinsic but also less intrinsic in their motivations based on the local Arabic culture. However, the degree of conflict between these two motivational tendencies became stronger among participants using French as a tool for communication. This research demonstrates the power of cultural representations based on language and adds to the arguments falsifying naïve beliefs in "perfect translations".

Key words: bilingualism, biculturalism, culture frame switch, values, extrinsic and autonomous motivation
\end{abstract}

\section{Introduction}

The end of the $20^{\text {th }}$ century brought many changes that have affected linguistic landscape of our times. Phenomena such as the development of communication, social mobility and universal migrations have led to an increase in the numbers of

Address for correspondence: Paweł Boski, Polish Academy of Sciences, Institute of Psychology, Jaracza 1, 00-378 Warsaw, Poland. E-mail: pboski@psych.pan.pl 
bilingual and bicultural individuals, who have internalized more than one culture and who speak the languages associated with each of those cultures. With regard to this group, it has often been noted, that bilinguals express different personalities in each of the languages they have acquired (LaFromboise et al., 1993). Thus, with bilinguals we have a two-in-one situation, instead of separated individuals encapsulated in their unilingual worlds. The problem of how such distant and usually separated linguistic systems coexist in individual minds, is an interesting research question for psychology.

An important theoretical inspiration to the research on bilingualism draws from studies on remote languages which led to linguistic relativity hypothesis (LRH). Initially formulated by Sapir and Whorf, LRH assumes that grammar, syntax and vocabulary determine the cognition of individuals. There is no language free cognition, and because languages differ so much among themselves, cognition of the persons who use them is also different (Sapir, 1978). The classical LRH is considered controversial which has largely to do with the lack of precision and sound empirical proof, typical for many formulations in social sciences about a century ago.

Today, the line of thought initiated by Sapir and Whorf has been continued in (at least) two separate strands: one is Wierzbicka's psycho-semantics; and the other is Roberson's cross-cultural research on color categorization in European and in traditional languages.

\section{Wierzbicka's psycho-semantic version of linguistic relativism}

Semantic analysis has demonstrated that words which seem to be equivalent in different languages, have different meanings. This conclusion applies equally to the words describing terms for basic emotions (Wierzbicka, 1994, 1999b) and for abstract cultural key-words (Wierzbicka, 2010).

In her last major work Wierzbicka (2010) analyzes the meaning of three such keywords in English: experience, evidence and sense. These are international concepts, well established in most European languages, and apparently not requiring translation. And yet the author has been able to demonstrate their English uniqueness when compared to French or German, Polish or Russian versions. Discussing, for example, experience, Wierzbicka finds its meaning broad, covering depersonalized or objectivized relations with the world as well as personally felt ongoing events, for which other words are used in other European languages (pp. 25-65) ${ }^{1}$. Unlike with other European neighbors, experience is considered as one of the cornerstones of English culture, philosophy of truth, etc.

Although Wierzbicka does not conduct empirical studies as practiced by psychologists she has offered some very useful semantic analyzes in domains of emotions and

\footnotetext{
"Experience should often be translated into Polish as "przeżycie" rather than "doświadczenie", like in such exemplary compounds: wonderful/terrific/exhilarating/horrendous/marvelous/experience. The personal aspect of doświadczenie is well illustrated in such phrases as: Życie go doświadczyto or Doświadczyt wiele dobra which can be neither translated as Life has experienced him nor He has experienced much benevolence. To avoid such personal connotations we do not say in Polish Psychologia doświadczalna but Psychologia eksperymentalna.
} 
color categories (Wierzbicka, 1999a, pp. 405-449). Niebieski (Polish) and blue (English) are different categories, according to her. The term niebieski describes only bright and medium dark shades of the color (lower value). In English, by contrast, the word blue describes equally bright and very dark shades of blue. This explication provides a convenient moment for turning to empirical studies on color cognition.

\section{Color categorization and color cognition}

In empirical psychology, the research tradition most relevant to linguistic relativity hypothesis is that of color categorization and perception. Earlier studies by Berlin \& Kay (1969), and by Heider-Rosch (Heider, 1972, Rosch, 1977) pointed towards universal cognitive processes in color perception, memory and learning. Irrespective of linguistic constraints, people were found more sensitive to color prototypes, defined exclusively as perceptual qualities (saturation). Results from more recent experimental studies, conducted by D. Roberson and her colleagues, in traditional and isolated cultures, have challenged those conclusions. Working among the Berinmo of New Guinea (Roberson et al., 2000), and among the Himba of Namibia (Roberson et al., 2004), whose indigenous languages hold five basic color terms, these authors have shown that processing color information, depends on linguistic categories. People differentiate and recognize color stimuli according to their linguistic boundaries which vary among languages and divide the color spectrum differently.

In their theoretical round-up of a series of studies conducted in New Guinea, Roberson and her colleagues conclude:

Our data show that the possession of color terms affects the way colors are organized into categories. Hence we will argue against an account of color categorization that is based on innately determined neurophysiology. Instead we propose that color categories are formed from boundary demarcation based predominantly on language. Thus, in a substantial way, we will present evidence in favor of linguistic relativity. (Roberson, Davies, Davison, 2000, p. 394)

This conclusion is then generalized to other domains beyond color naming:

The present set of experiments prompt the conclusion that the case of color categorization may not, after all, be special, but rather follow the pattern observed for other areas of cognitive and perceptual categorization in being determined by linguistic relativity. (Ibid., p. 396)

The evidence that has been discussed so far assumes cross-cultural/linguistic comparisons, between separate monolingual groups. A related problem arises, when one considers cognitive functioning among bi-/multi-lingual individuals. If the language of communication determines cognition, we should expect that individuals who communicate fluently in two or more languages will have dif- 
ferent interpretations of reality, depending on the language they actually use. The aforementioned problem has drawn the attention of psychologists and has opened a new field of research, typical for intercultural psychology. Here, bicultural and/or bilingual individuals are tested in either of their competences to see if this alternation will change their cognitive or axiological functioning.

\section{Culture frame switching}

Culture frame switching consists of cognitive priming process through the use of cultural icons (symbols). A well known demonstration of this mechanism was provided by Hong, Morris, Chiu, \& Benet-Martinez (2000) with a series of studies on Chinese-Americans. These researchers primed their participants with American or Chinese symbols and then tested their causal attributions regarding animated fishmovements. Results proved effectiveness of this procedure: Participants primed by American cultural symbols became more internal in their causal attributions, while those primed by Chinese symbols switched to more external attributions. This paradigm was continued by Benet -Martinez who found that the frame- switching mechanism interacted with the integrated or conflicting bi-cultural identity. While performance of cognitive tasks among integrated biculturals was attuned to the priming condition; those with conflicting identity displayed reversed or paradoxical patterns of attribution, i.e. opposite to the direction of priming (Benet-Martinez, Leu, Lee, \& Morris, 2002).

There is no reason why the frame-switching mechanism be operating only in cognitive domain such as attributions, and not in the sphere of values. In the first study conducted in our lab by Osińska (2007), bicultural adolescents from the American School of Warsaw were primed with Polish or American symbols and then they filled value questionnaire with humanism and liberalism scales, which differentiate between Polish and American cultures, accordingly (Boski, 2012). Osińska demonstrated lower endorsement of humanist values under Polish identity priming condition. To explain this paradoxical finding, a concept of conflicting bicultural identity integration (Benet-Martinez, Harricot, 2005) was referred to.

\section{Consequences of language switch among bilinguals}

It should be noticed that the culture frame switch paradigm takes place with the visual-symbolic code and it largely bypasses the issue of language use ${ }^{2}$. Since it is linguistic relativity hypothesis which provides us with the context for our research, the distinction between verbal and visual codes of cognition and communication is important (Winczo, 1994); even though the central hypothesis on dual functioning remains unchanged. An important study on the effects of linguistic switch on priming culture relevant implicit theories of personality was reported by Hoffman, Lau, Johnson (1986). These authors were able to demonstrate that depending on

\footnotetext{
2 Subjectively assessed bilingualism is a criterion for participant selection in Benet-Martinez studies, yet the priming procedure is done on visual material only.
} 
language condition in which a story was written, bi-lingual Chinese-Americans used different set of associations. When they read the story in Chinese, the shi-gù schema was activated, portraying a character of subtle manners, broad-minded, family-oriented and introverted; this led to an overall story completion in line with the schema. However, when its English version was presented, the initial story primed an artistic, Bohemian character which led to different associations in the story completion. Results of this investigation have obvious consequences for cross-cultural adoption of literature works: translations do not create equivalent versions and lead to differences in reception of the original oeuvre d'art.

\section{Studies on values}

Values are defined as "desirable, trans-situational goals, varying in importance, that serve as guiding principles in people's life." (Schwartz, 1992; 1996, p.2) In his theory Schwartz considers values as universal, i.e. equivalent in meaning, structure and regulation, when translated into all languages of his multi-cultural research project. This idea stands in opposition to the hypothesis of linguistic relativity as advanced in the works of Wierzbicka (2010). Since values are considered as the building blocks of cultures and of individual worldviews, they should be sensitive to the frame switching mechanism, introduced and discussed before.

In an early study by Bond \& Yang (1982), Chinese bilinguals who responded to a questionnaire in English endorsed more values and norms associated with the English-speaking world than Chinese bilinguals who responded to the same questionnaire in Chinese. A more recent investigation found the Hong Kong bilingual-Chinese managers who responded to a values questionnaire in English display ideas closer to a group of American managers in the US than the bilingualChinese managers who responded to the same questionnaire in Chinese (Ralston et al., 1995). Similarly, when bilingual young adults from Hong Kong were asked to describe themselves, those responding in Chinese used more collectivistic and fewer individualistic terms, than those who responded in English (Kemmelmeier, \& Cheng, 2004). Also studies conducted among bilingual children from Hong Kong showed that those answering in Chinese reported higher agreement with Chinese interdependent values, and lower agreement with Western independent values, than children answering in English (Wang et al., 2010).

Finally, Ross, Xun, and Wilson (2002) interviewed Chinese-born bilingual young adults living in Canada. The authors asked participants to describe themselves and to rate statements reflecting Chinese cultural values (e.g., "Modesty leads to success, pride leads to failure"). Those who participated in Chinese language condition described themselves in more collective terms and endorsed Chinese values more strongly than those who were surveyed in English.

These studies show us, that bilingual individuals who are users of two systems of meanings also have two systems of values, which change depending on culture-activation. It seems fair to conclude that values are not as stable and trans- 
situational as claimed by Schwartz. Depending on the language in which they are approached, bilinguals respond as monolinguals from respective cultures. With these studies we are also unable to answer whether the findings reflect cross-cultural differences in value importance, or also in their meaning.

The contribution which will be presented below shifts the cultural-geographical focus from Chinese-Americans to bilingual Tunisians; it also investigates community based vs. internalized values, extrinsic vs. autonomous normative motivation, and normative conflict.

\section{Bilingualism and culture in Tunisia: Islamic and French influences}

The main goal of the research reported in this paper was to establish and empirically document the language frame switching effect in the domain of values derived from Arab-Islamic and French origins. We chose to study this phenomenon in Tunisia which is the land where these two traditions coexist and where two languages are used at large.

Tunisia for centuries was the land of interpenetration and under the influence of many cultures. The difference of these impacts can be seen by studying the history of this area, beginning from the Phoenician colonization, to the influence of Roman, Germanic, Byzantine, Arab, Persian, Turkish and ending with French colonization (Dziubinski, 1994). However, not all of the mentioned cultures have played an equally important role in shaping the current Tunisian identity. Most importantly for population structure was the Arab conquest and Islam. The effects of this process are prominent in the society and culture of today's Tunisia which is a country, with about 97\% of Arab population, and Arabic being the official language. The main religion is Sunni Islam, whose followers are estimated approximately $98 \%$ of the total population. Consequently, Tunisia belongs to the region of Arab-Islamic culture, where specific standards of behavior are imposed. The main sources of these values derive through the Koran and hadiths (tradition of the Prophet), (Machut- Mendecka, 2003). At the top of the hierarchy of values is godliness. Religiosity is also strongly associated with wisdom. According to the Qur'an a wise person is someone who believes in God and follows the religious rules (Koran, 35:28) with total submission to God, patience and acceptance of one's own destiny. Other values included in the Qur'an are goodness, kindness, courtesy, modesty, temperance and moderation. Islam also enjoins respect for the parents and the elderly (Machut- Mendecka, 2003).

In the Arab-Islamic culture, current values that originate from the pre-Islamic period are known as the jahiliya. These are the values of honor, dignity, social harmony, absolute loyalty and solidarity with relatives and strong relations with family. These collective trends can be observed in the Muslims daily lives.

The Muslim family is patriarchal, with man having a decisive role. The Qur'an emphasizes the superiority of men over women (Qur'an, 2:228), which leads to clear distinction between male and female social roles. Man is responsible for maintaining 
his family; while woman keeps household together and raises children. These values are the backbone of the traditional Arab-Muslim culture of which Tunisians are members. The communion of culture, religion and language in Tunisia is so strong, that the traditional Arab values are still the most important source of influence for individual attitudes and conduct.

However, not only Arabic influences have an impact on the current Tunisian identity and culture. An important contribution to this area was also made by France, which had imposed in 1881 on Tunisia her lasting for 75 years protectorate. Tunisia is a geographical region of North Africa, known as the Maghreb and the Tunisians and Algerians together with the Moroccans are culturally Maghrebians, which means among other things, that they are strongly influenced by French culture. The principle of a dual culture was adopted since independence in 1958. Until today, la presence française has been felt in all aspects of Tunisian culture, especially in education and in business, where French has become the country's second official language. In Tunisian schools some subjects are taught in French, others in Arabic (Wiechecki, 1973). Permanent contact with French culture and language, allowed a relatively free flow of secular-republican values to traditional Arab culture. These values include: freedom, equality, democracy, secularism, intellect and the ability for logical and critical thinking (Jarosz, 1992).

The position of France on cultural map of the world, shows high levels of affective and intellectual autonomy (i.e., hedonism, exciting life, subjectivity, broad horizons and curiosity) based on Schwartz's ( 2004) research project. The same study has characterized the French culture by high position of egalitarianism associated with equality and justice, as well as harmony corresponding with universalism. This profile remains in deep contrast with Islamic cultural region, characterized by embeddedness (traditionalism) and hierarchy.

The above considerations lead us to reflect on current Tunisian identity, which consists of values and standards of behavior deriving from both cultures: French and Arabic; expressed in the two languages, respectively. These issues seem especially interesting, when taking into account differences and contradictions between the traditional Arabic and French liberal values. It is difficult to reconcile moderation and temperance typical for Arab-Muslim culture, with French hedonism; or traditional division of gender roles with equality of men and women. It is easier to conceive coexistence of these conflicting values in Tunisian culture, expressed side-by-side in the two languages. It becomes more difficult to imagine their integration at the level of an individual person.

\section{Current Research}

\section{Influence of language}

In line with the hypothesis of linguistic relativism, languages facilitate the process of transferring values and maintaining their meanings embedded in their 
respective cultures. Consequently, it can be assumed that bilingual and bicultural Tunisians are the carriers of two systems of meanings, which contain different value systems. In fact, Tunisians communicate in both languages: Arabic and French. Both languages are important in Tunisian social life. Arabic is the language of religion, literature and public life, while French plays an important role in public life: education, business, international relations, and tourism ${ }^{3}$. This linguistic segmentation and specialization should result in Arabic language being better suited than French for expression of traditional Islamic culture. The opposite tendency should occur in the domain of secular-individualistic values, which should be better represented and familiar in French, than in Arabic. This reasoning leads us to formulation of the central hypothesis of this work.

We expected that with the survey conducted in Arabic, Tunisians should attach greater importance to traditional Islamic values than in the condition when the survey would be conducted in French. However, with research conducted in French, the importance of the values associated with secular-individualist culture should be on the rise.

Extrinsic vs. autonomous motivation. The issue of motivation, is essential when discussing internalization (identification) of values. As it was assumed that language can prime only those cultural values to which they provide adequate verbal expression, we also decided to check different types of motivation that can be language sensitive.

The self-determination theory by Ryan and Deci (2000) postulates a motivational continuum spread from purely extrinsic (to satisfy someone's expectations) to autonomous self-determination (in line with personal convictions and a sense of freedom).

Traditional values are well grounded in family and local community and they may trigger extrinsic type of motivation, to conform. But they may also become effectively internalized, forming conditions for autonomous motivation. We wanted to compare extrinsic and autonomous motivation, irrespective whether their origin was Arabic traditional or French individualist. Participants interviewed in Arabic were expected to act on traditional values both for extrinsic and for autonomous reasons to a greater degree than Tunisians surveyed in French.

Participants interviewed in French were expected to have stronger autonomous motivation in individualist value domains, than their colleagues interviewed in Arabic.

It is the central tenet in Schwartz's theory, that values stay in conflict; examples of such conflicts are pairs of values: hedonism and traditionalism, self-direction and conformity. Such conflicts occur intra- as well as inter-personally; generations of parents are usually more traditional than the offspring. It was assumed that the differences between the family/community expectations and own convictions

\footnotetext{
${ }^{3}$ To complicate the matters, Tunisians use, in their daily transactions, a specific Tunisian dialect, which is a combination of Arabic and French. This creolization is a peculiar linguistic situation, which may have a significant impact on the present values in Tunisian culture.
} 
may become more pronounced in French language condition, because the distance between both sides appear larger.

\section{The influence of generation}

The degree of acquiring a second language in a given population largely depends on political circumstances (dominance of an external power), expediency, and fashion - which become transmitted into school curricula. Each of these reasons goes through changes from one historical period to another ${ }^{4}$. In Tunisia, public access to education was introduced in Tunisia in 1956, and the first literate generation of bilingual persons was born between 1950 and 1970. Current university students make the next generation of people fluent in both languages. Cultural orientation of these age groups may differ because the older generation was usually raised by monolingual parents, illiterate and deep-rooted in the Arabic tradition. This is different from the younger generation that has been educated in a bilingual environment in contact with French culture and language. It can be assumed that the generation 1950-1970 will pay more attention to traditional Arab values, than the generation of their children.

\section{Method}

\section{Participants}

Our sample consisted of 83 bilingual residents of the cities Sousse and Monastir in Tunisia. 52\% of the respondents were students from the faculties of mathematics and engineering, studying at the Technical University of Monastir (Université de Monastir), aged between 20 to 26 years. People in the age group from 40 to 55 years, who were the first bilingual generation also participated in this study (48\% of participants). Individuals from this group were selected from Sousse and Monastir citizens. The survey was conducted from February to March 2010. Students were examined at the University of Monastir, while adults were contacted at their private homes in of Monastir and Sousse.

To manipulate the language variable the research was conducted either in French or Arab. The selection of participants to language conditions was random.

Arab-French Value Survey. To measure the dependent variables, an author designed questionnaire was used. It consisted of 39 value statements attributed to family and self; intentionality to follow them; and conflict. The inspiration for the creation of this instrument was a Profiles Value Questionnaire, used to measure values (Schwartz, Lehmann, Roccas, 1999).

Items relating to Arab-Muslim tradition, have been borrowed from the Koran and hadiths (Koran, 1986; Hadith, 2010.) These items refer to traditional and collec-

\footnotetext{
${ }^{4}$ In Poland for instance, knowledge of Russian spread in generations which grew up under tsarist Russia's dominance in late $19^{\text {th }}$, and during communist rule in mid $20^{\text {th }}$ century. The unquestionable position of English is the matter of last 25 years.
} 
Table 1

37. Remember that woman's destiny is taking care of the family, and not pursuing her job or career

a This opinion is typical for my family environment. I have heard it many times in my life

$\begin{array}{lllll}1 & 2 & 3 & 4 & 5\end{array}$

b This opinion is a reflection of my own beliefs. I strongly believe it

c If I follow this rule, it's because others expect it from me

d If I follow this rule, it's because, that these are my personal beliefs

$\begin{array}{llll}1 & 3 & 4 & 5\end{array}$

$\begin{array}{lllll}1 & 2 & 3 & 4 & 5\end{array}$

$\begin{array}{lllll}1 & 2 & 3 & 4 & 5\end{array}$

e When I follow this rule I feel conflict between duty to family environment, and my own sense of righteousness

tive values characterizing the Arab-Muslim culture such as: obedience and respect for elders, family, honor, loyalty to relatives, the acceptance of one's own destiny and place in life, patience, godliness, harmony, kindness, traditional gender roles, goodness, honesty, truthfulness, keeping traditions, wisdom associated with godliness, submission to the will of the community and care for one's own good name.

The questionnaire also included secular-individualistic values associated with French culture. They have been selected from such documents as the French Constitution of 1956 and the preamble to Universal Declaration of Human Rights, which was adopted by General Assembly of United Nations, in 1948. Moreover, items appearing on Schwartz's value types of affective and intellectual autonomy, and egalitarianism where France scored very high, were taken into account. Item sample of these values include: freedom of choice, equality, subjectivity, autonomy of thinking, broad horizons; hedonism; universalism, skills of logical and critical thinking.

Statements concerning values have been formulated in imperative format; for example: Do not thrust yourself forward and do not focus the attention of others; Always openly express your opinion, no matter what others say; Remember, that woman's destiny of is to take care of the family, and not pursuing job or career. As Table 1 shows, participants were answering five facets of each value.

An exemplary item illustrating these facets is reported below:

Remember that woman's destiny is taking care of the family, and not pursuing her job or career.

- Group value (Q1)

This opinion is typical for my family environment. I have heard it many times in my life;

- Personal value (Q2) This opinion is a reflection of my own beliefs; 
- Extrinsic intentionality (Q3) If I follow this rule, it's because others expect it from me;

- Intrinsic intentionality (Q4) If I follow this rule, it's because, of my personal beliefs;

- Conflict (Q5)

When I follow this rule I feel conflict between duty to family environment, and my own sense of righteousness.

The distinction between values shared by family/community (Q1) and personal values (Q2) is important. The two levels may be compatible but a possibility of their conflict (Q5) is always there; and inter-generation comparisons are investigated for this purpose. Another distinction, between $(\mathrm{Q} 3)$ and $(\mathrm{Q} 4)$, concerns intentionality of value implementation: the first one is an extrinsic normative influence, and the other is an intrinsic commitment, as the theory of self-determination proposes. The two pairs of questions (Q1 and Q2 vs. Q3 and Q4) correspond to each other but are not equivalent. If an external value is well internalized, it will become an intrinsic intention. A personal value may not be transformed into an intrinsic reason for action.

Translation. The questionnaire was initially prepared in Polish. The Arabic version was translated by a bilingual and bicultural person, whose mother is Polish and father is Jordanian and who spent many years of his life in both countries. The French version was prepared by another bilingual and bicultural person, whose mother is Polish and father is a French person; she lives permanently in Paris.

The two versions were then compared by a Tunisian, residing in Poland and fully bilingual in both languages of the study. The final stage of verification occurred in Tunisia by two Arabic-French bilinguals, one of them being a teacher of French language.

\section{Procedure}

Respondents were randomly assigned either to the Arab or to the French version of the questionnaire. The questionnaire consisted of the instructions, sociodemographics, and the Arab-French Value Survey. There were no indications of lack of clarity or ambiguity in any of the two linguistic versions of the survey ${ }^{5}$.

\section{Results}

\section{Values of the family environment}

To identify the structure of family values and beliefs, a factor analysis was performed on the answer set to Q1 question. Using the scree-plot criterion, the analysis established three factors to be extracted from the data. Promax rotation

\footnotetext{
${ }^{5}$ The author of the study observed however, that it usually took longer (especially for participants from the parent generation) to fill out the French version of the survey. This may indicate dominance of Arabic language in our sample.
} 
was applied. The factors explained together $35.4 \%$ of variance. The first factor (eigen value $=8.74$ ), has been labeled Individualism, its reliability coefficient $\alpha=0.84$. The scale loads ( $>0.40)$ on 11 items, such as: $A$ word of a woman carries the same weight as a word of a man (0.69); Life is meaningful only when you dedicate it to some important idea (0.68); Always tell the truth, even if it is hard to your dear ones (0.65).

The second factor, called Traditionalism, with eigen value $=2.87$, and $\alpha=0.82$. The scale has 12 items. On top of them are: Care for the good name of your family (0.71; Behave in a way that you were taught at home (0.64); Be a religious person (0.59). The third factor (9 items, eigen value $=2.17$ ), $\alpha=0.74$, displays a similar orientation, and has been called Conformity: Be kind to others, even when you don't like them (0.59); Be gentle, respect your parents and elders (0.56); Strive for a positive image of yourself with others (0.56).

To test the hypotheses on the impact of language and generation on values attributed to the family environment, a two-factor analysis of variance was carried out in the 2 (Language: Arab vs. French) x 2 (generation: adults vs. student) design. Dependent variables were scales the three factorial scales. Results of these analyses can be seen in the first three rows of Table 2 .

Of the three dimensions of values attributed to the family milieu, language of responding contributed to significant differences in two of them: tradition and conformity. These values were pronounced at higher level in Arabic than in French; the difference in tradition was very substantial. Individualism, on the other hand, was expressed at the same level in both languages.

These differences were also replicated in inter-generation comparisons. Here too, the scores on tradition and conformity were higher among parents than among student generation; the effects were weaker though than those due to language.

\section{Personal values}

To identify the structure of personally endorsed values, a similar factor analysis was performed and three factors explaining 33.4\% variance emerged. Psychological meaning of these factors coincides with the previous analysis: they were defined, in descending order of eigen values as tradition $(\alpha=0.79)$, individualism $(\alpha=0.77)$, and conformity $(\alpha=0.63)$.

To verify whether the language and generation have an impact on personal values, two-factors analysis of variance was carried out 2 (language: Arab vs. French) x 2 (generation: students vs. adults). Dependent variables were the three factorial scales. Results of that analysis are presented in rows 4-6 of Table 2.

A significant main effect of language on traditional values was found again. It turned out that the personal convictions in this domain were higher for those participants who completed the questionnaire in Arab, than when people filled it in French. No such effects were demonstrated for the other two scales; individualist values, in particular were immune again for their linguistic expression. In addition, a significant effect for generation was obtained in traditional values. Personal en- 
Table 2

\begin{tabular}{|c|c|c|c|c|c|c|c|c|c|}
\hline & \multirow{2}{*}{ Scale } & \multicolumn{2}{|c|}{ Language } & \multirow{2}{*}{$\mathrm{F}(1,79)$} & \multirow{2}{*}{$\eta 2$} & \multicolumn{2}{|c|}{ Generation } & \multirow{2}{*}{$\mathrm{F}(1,79)$} & \multirow{2}{*}{$\eta 2$} \\
\hline & & Arabic & French & & & Parents & Students & & \\
\hline \multirow{3}{*}{ 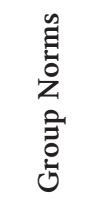 } & Individualism & 3.62 & 3.37 & 2.05 & 0.02 & 3.61 & 3.39 & 1.44 & 0.02 \\
\hline & Tradition & 4.39 & 3.90 & $16.74^{* * * *}$ & 0.18 & 4.30 & 4.02 & $4.95^{*}$ & 0.06 \\
\hline & Conformity & 4.31 & 4.01 & $5.80^{*}$ & 0.07 & 4.30 & 4.02 & $4.96^{*}$ & 0.06 \\
\hline \multirow{3}{*}{ 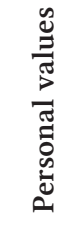 } & Tradition & 4.01 & 3.62 & $6.96^{* *}$ & 0.08 & 3.98 & 3.66 & $4.82^{*}$ & 0.06 \\
\hline & Individualism & 3.94 & 3.83 & $<1$ & & 4.00 & 3.77 & 2.57 & \\
\hline & Conformity & 4.06 & 4.10 & $<1$ & & 4.17 & 3.99 & 1.72 & \\
\hline \multirow{3}{*}{ 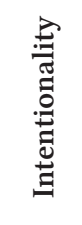 } & Extrinsic & 4.02 & 3.38 & $15.47^{* * * *}$ & 0.16 & 4.00 & 3.41 & $13.43^{* * * *}$ & 0.15 \\
\hline & Tradition & 4.28 & 3.79 & $18.50^{* * * *}$ & 0.19 & 4.24 & 3.83 & $13.23^{* * * *}$ & 0.14 \\
\hline & Individualist & 4.29 & 4.12 & $<1$ & & 4.26 & 4.15 & $<1$ & \\
\hline \multirow{2}{*}{ 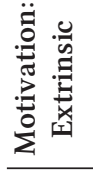 } & Social norms & 18.13 & 13.92 & $23.27^{* * * *}$ & 0.23 & 17.95 & 14.26 & $16.47^{* * * *}$ & 0.17 \\
\hline & Individualism & 15.04 & 12.41 & $5.37^{*}$ & 0.06 & 15.00 & 12.45 & $5.02^{*}$ & 0.06 \\
\hline \multirow{2}{*}{ 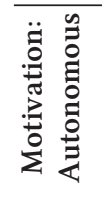 } & Traditionality & 18.83 & 15.79 & $16.94^{* * * *}$ & 0.18 & 18.44 & 16.19 & $9.28^{* *}$ & 0.11 \\
\hline & Individuality & 17.72 & 17.24 & $<1$ & & 18.36 & 16.60 & $4.32^{*}$ & 0.05 \\
\hline 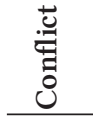 & $\begin{array}{l}\text { Self - Social } \\
\text { environment }\end{array}$ & 2.13 & 2.62 & $6.50^{*}$ & 0.08 & 2.25 & 2.49 & $1.67, \mathrm{~ns}$ & \\
\hline
\end{tabular}

Note: ${ }^{* * *} \mathrm{p}<0.0001 ;^{* * *} \mathrm{p}<0.001 ;{ }^{* *} \mathrm{p}<0.01 ;{ }^{*} \mathrm{p}<0.05$

dorsements of values and beliefs among middle aged adults reflected the traditions to a greater extent than among students.

\section{Intentionality}

Since the regulatory role of values is situationally constrained, willingness to follow them as guiding principles of action was measured. There was a single factor 
of external demands (Q3) which explained $39.77 \%$ of total variance, irrespective of their content. A very strong effect of language was found, such that participants interviewed in Arab attributed axiological intentions much stronger to external sources than their colleagues in interviewed in French (see row 7 in Table 2). A similar tendency was found for generation groups, where parents scored higher than the students.

With intrinsic intentionality, two factorial scales reflected the distinction between traditional (eigen value $=6.87 ; \mathrm{n}=15$ items, $\alpha=0.84$ ); and individualist (eigen value $=2.61 ; \mathrm{n}=7$ items, $\alpha=0.60$ ) values. Linguistic version mattered only for the former scale (see Table 2, row 8). When participants were interviewed in Arabic, they believed to be more intrinsically directed to follow traditional values (Establishing family and subordinating all activities to family life; Obedience to the elders; Positive regard from others) than their colleagues who were interviewed in French. A similar tendency was found for generation groups, where parents reported stronger, than students, intrinsic intentionality to follow traditional values.

\section{Extrinsic motivation}

Locating values in family/community environment, and intentionality to follow these values because of external expectations (or normative pressures), are two related but different matters. Theoretically, these two constructs jointly contribute to extrinsic motivation, also called press in classical literature. Extrinsic motivation should be a product of family values and intentionality to enact them based on external expectations. This reasoning is justified on empirical grounds, where external intentionality was correlated with family individualism $(\mathrm{r}=0.54, \mathrm{p}<0.001)$, tradition $(\mathrm{r}=0.56, \mathrm{p}<0.001)$, and conformity $(\mathrm{r}=0.59, \mathrm{p}<0.001)$. Based on this evidence, indices of extrinsic motivation were created by multiplying each of 39 $(\mathrm{i}=1, \ldots ., \mathrm{n})$ family values $(\mathrm{FV})$ by their corresponding intentionalities (F_INT):

$$
\text { Extr }_{\text {mot. }}=\left[\sum_{\mathrm{i}=1}^{\mathrm{n}=39}=\mathrm{FV}_{\mathrm{i}}{ }^{*} \mathrm{~F}_{-} \mathrm{INT}_{\mathrm{i}}\right]
$$

Another factor analysis was performed on thirty nine indices of extrinsic motivation. Two factors explaining together $45.5 \%$ variance were extracted. The first factor was called traditional social norms (eigen value $=15.36 ; \mathrm{n}=14$ items, $\alpha=0.92$ ), with highest loading items: Maintain family traditions and customs; Always show respect to your parents and elders; Don't push yourself to the forefront. The other was a factor of individualism (eigen value $=2.39 ; \mathrm{n}=13$ items, $\alpha=0.92$ ): Try to understand the complexities of the world today; Set your own goals; A word given by a woman carries the same importance as that of a man. Based on these two newly created variables, a two-factor analysis of variance was carried out in the 2 (language: Arab vs. French) ${ }^{*} 2$ (students vs. adults) design. Summary results 
are reported in rows 10 and 11 of Table 2 . A highly significant main effect of language on traditional social normative motivation was found, such that individuals filling in the questionnaire in Arabic were considerably more ready to regulate their behavior in accordance with such prescriptions than those interviewed in French. Also, a marginally significant effect of a similar nature was found for extrinsic pressures towards individualism. Similar tendencies were reported for inter-generation comparisons.

\section{Autonomous motivation}

For the construct of autonomous motivation (Autonom. ${ }_{\text {mot. }}$ ), a scale was derived by a similar formulae to that of extrinsic motivation; this time it was the sum of thirty nine products of personal values (PV) and their corresponding intentionalities (P_INT):

$$
\text { Autonom. }_{\text {mot. }_{\text {. }}}=\left[\sum_{\mathrm{i}=1}^{\mathrm{n}=39}=\mathrm{PV}_{\mathrm{i}}{ }^{*} \mathrm{P} \mathrm{INT}_{\mathrm{i}}\right]
$$

Two factors explaining $27.24 \%$ variance, and paralleling content the content of extrinsic motivation were extracted. Traditionality (eigen value $=8.10 ; \mathrm{n}=22$ items, $\alpha=0.86$ ) with highest loading items: Do what elders believe is right; Don't push yourself to the forefront; Always show respect to your parents and elders. Individualism (eigen value $=2.53 ; \mathrm{n}=10, \alpha=0.73$ ) was the second factor: Develop your skills of logical and critical thinking; Think and act rationally; Broaden your horizons. This was followed by a two-factor analysis of variance, using the same design as before, 2 (language: Arab vs. French) x 2 (age: students vs. adults). Relevant results are summarized in rows 12 and 13 of Table 2. It was found again that people exposed to the Arab version of the questionnaire displayed higher level of autonomously motivated traditionality, than their colleagues interviewed in French; no linguistically determined difference was reported in the domain of individuality.

The interaction between language of expression and traditional vs. individualistic aspects of autonomous motivation $\left[\mathrm{F}(1,79)=10.04, \mathrm{p}<0.01, \eta^{2}=0.13\right]$ further indicates that traditional aspects of autonomous motivation are more expressed in Arabic $\left[\mathrm{F}(1,79)=3.92, \mathrm{p}<0.05, \eta^{2}=0.05\right]$, while individuality is more articulated in French $\left[F(1,79)=6.24, p=0.015, \eta^{2}=0.07\right]$.

In an overall analysis, where unitary motivational constructs were compared, three main effects were observed: autonomous motivation was much stronger than extrinsic $\left[\mathrm{F}(1,79)=23.93, \mathrm{p}<0.001, \eta^{2}=0.23\right]$; participants were more motivated to uphold cultural norms when they responded in Arabic than in French $\left[F(1,79)=18.71, p<0.001, \eta^{2}=0.19\right]$ and when they were one generation older $\left[\mathrm{F}(1,79)=14.87, \mathrm{p}<0.001, \eta^{2}=0.16\right]$. The strongest was autonomous motivation of parent-generation interviewed in Arabic $(M=19.05)$, and the weakest was extrinsic motivation of student generation interviewed in French $(M=12.04)$. 


\section{Conflict}

A scale measuring the level of conflict has been verified by factor analysis. One factor sufficiently accounted for the total of conflict variance, explaining its $41.3 \%$. That factor is characterized by high reliability, Alfa $=0.952$.

To check, whether language and generation had impact on level of conflict, a two-factor analysis of variance was performed on these variables; its results are presented in row 14 of Table 2. Conflict between external pressures (or expectations) and self-generated rules of conduct, was stronger when French was the language of interviewing. This is the first time and only when any scale results in French were above those obtained in Arabic.

Next, regression analysis was conducted to see which aspects of normative motivation predict the conflict level. Four motivational constructs were regressed on conflict scale as outcome variable. There were no effective predictors of conflict when Arabic was the language of communication. It was much different when the study was conducted in French. Here, on both scales individualism made the difference $\left[\mathrm{R}_{\mathrm{adj}}{ }^{2}=0.30 ; \mathrm{F}(2,37)=9.51, \mathrm{p}<0.001\right]$. As an element of motivational autonomy, individuality was a negative predictor of conflict, $\beta=-0.61, p<0.0001$, but as a factor in extrinsic positive, individualist pressures positively contributed to conflict level, $\beta=0.27, \mathrm{p}=0.06$.

\section{Discussion}

In the broadest sense, this paper belongs to the tradition of linguistic relativity hypothesis; in a more precise way, it is a study comparing psychological functioning of bilingual persons in the domain of cultural values. The main goal of this investigation was to examine whether the language switching effect, initially explored with Chinese-Americans, can also be found in value domains of bilingual Tunisians. In contrast to the paradigm established by Benet Martinez and her colleagues, we did not use cultural primes (symbols of cultural identity) but language as a tool of communication and data collection. Specifically, we tested whether bilingual Tunisians would endorse various facets of traditional and individualistic values differently, depending on language of interviewing.

Based on previous evidence (Boski, 2008), we predicted that depending on the use of language, (Arab vs. French), bilingual Tunisians would activate standards, compatible either with Arab or with French culture. Research hypotheses were formulated relative to family milieu values, and to personal standards. It was predicted that individuals examined in Arab, would declare traditional Arab values as more central in their family environment and would endorse them to a greater degree than respondents examined in French. These hypotheses were confirmed by the research findings. Values based on the traditions, which are the root of Arab culture, are more adequately reflected in the language to which 
they belong. The higher scores for traditionality in Arabic were not restricted to extrinsic aspects of values, intentionality and motivation; they were equally present on the intrinsic side of the continuum, which reflects internalized values and autonomous motivation.

The hypothesis predicting a similar effect of French language on priming of liberal values, was not confirmed. Like with traditionality, we had individualistic components in five classes of variables: (i) family/community norms; (ii) personal values; (iii) action intentionality, (iv) extrinsic motivation; and (v) autonomous motivation. Neither of these five individualistic facets of regulation was expressed in French above the level observed in Arabic. If anything, there was a slight tendency for Arabic dominance maintained. Trying to explain this asymmetry, we should return to the question of Tunisian identity. It is hard to overestimate the importance of Arab influences and their dominance in Tunisians daily life.

Despite the strong French influence during the colonial and post-colonial period, Tunisia is a country which belongs to the Arab-Islamic cultural region, whose population is conscious of its own membership to the Arab cultural community. Identification with Arab culture and its values is stronger than the bonds attaching to French culture 6 . The role of Muslim religion, and not the secular republican spirit as in France, remains central. For this reason, we cannot talk of full biculturalism among Tunisians.

Also, French is not an adequate tool to express traditional Muslim values rooted on Koran and hadiths. Arabic is the language of rituals and prayers for all Muslims; translations which miss that context loose also appeal. Traditional Arab values translated into French have lost their original meaning or were distorted (which is not a result of faulty back translation). It is possible that the traditional and conformist values, which have positive connotations in Arabic and are seen as desirable, worthy of respect, become pejorative in a French translation; and even for a bilingual Tunisian.

The same line of argument can explain why Tunisians interviewed in Arabic were characterized by both high external and autonomous motivation. Though theoretically not anticipated, it looks as if autonomous and external motivation are largely compatible when measured in Arab. Values important for the family environment are also internalized by individuals, so that the two types of motivations appear together, without causing internal conflict. However, the level of conflict increases, when French is the language of communication. Probably, French language activated the standards which are in conflict with the more internalized Arab values and created sense of foreignness and cognitive dissonance, and confrontation between the two systems of values.

\footnotetext{
${ }^{6}$ Even the Arab Spring, which initiated the process of political democratization in North Africa and the Middle East, starting with the jasmine revolution in Tunisia in early 2011, by unseating former president Zin Al-Abidin Ben Ali, took place under traditional and not Western slogans.
} 


\section{Culture frame switch: Identity symbols vs. language of communication}

Psychological functioning of bi-lingual/-cultural individuals has been studied through two methods of priming. First is the typical frame switching paradigm, where symbols of visual identity are used as primes; also dependent variables are nonverbal in this approach, as the popularity of fish-in-the-aquarium attribution task attests.

The symbols used as identity primes are obviously very distinct for each culture: they lack equivalence by their very nature, and are comparable only in a functional, abstract sense ${ }^{7}$. Supposedly, cultural origins responsible for differences in psychological functioning can be accessed with such priming. We still do not understand thoroughly what are the mechanisms leading from identity priming among bicultural individuals to the changes in their cognition, such as the patterns of attribution. What is the chain linking exposure to the icon of Confucius or Abraham Lincoln, to differential preferences of holistic or analytical cognitive style among Chinese-Americans? - The distance separating cause and effect is large in this case, several links are still missing, which makes the empirical findings so intriguing and puzzling.

Linguistic-verbal priming rests on quite different set of assumptions. Any foreign language is even less comprehensible to the non-users than pictorial symbols which always represent "something". But, it is practically assumed that through proper translation, semantic equivalence can be established between two sets of concepts, such as values. All test adaptations throughout the world are based on these common sense assumptions. Consequently, this approach does not allow for cross-cultural differences based on verbal cognition. Furthermore, a bilingual person - being herself a competent interpreter - should respond "identically" to each version of the questionnaire.

This absolutist approach has been criticized in different contexts (e.g. intelligence testing). In our review of literature, two strands of evidence have been discussed: (i) the most recent studies on linguistic color categories and color cognition by Roberson; and (ii) the psycho-semantic work of Wierzbicka. Both are the contemporary versions of the classical linguistic relativism hypothesis. The contributions by Roberson $(2000,2004)$ show that ideal translation is impossible because two linguistic systems may not correspond each to the other: their categories cut the world differently. Wierzbicka (1999b, 2010) adds to this, that even with abstract concepts, which form the quintessence of values, and are represented by corresponding terms in many languages, important cultural connotations are lost in translation.

Our study on bilingual Tunisians confirmed the ideas of these authors. Parts of Muslim cultural heritage which is encapsulated in Arabic language, are lost in

\footnotetext{
Pictures of popular heroes are often used as symbols of cultural identity. Icons of president Abraham Lincoln, Winston Churchill, and Józef Piłsudski represent very different persons in their respective countries and their common denominator is a category of leader-politician. Halloween and All Saints Day are back-to-back in calendar but represent very different symbolic traditions in coping with death and eternity.
} 
translation to French, affecting participants' transient valuation and motivation. But the process is asymmetrical, concepts and values originating from French culture seem to be not affected when translated into Arabic. Are they more universal?

\section{Implications for future research}

Cultural identity can be primed via pictorial and verbal codes. This important distinction, which has been well elaborated in general psychology, has not been sufficiently addressed in the literature on biculturality and bilingualism. Future research should compare the efficiency of both procedures (general and domain specific) and give us a better understanding of their underlying mechanisms.

Languages are separate systems but they are dynamic and affect each other. Bilinguals not only switch from one of these standard systems to another but they also function at the boundary, "grey zone". In Tunisia the daily language of communication is a specific Tunisian dialect, and standard Arab sounds like a foreign language. A similar creolization occurs at many border regions. Using standard Arab and French, created somehow artificial conditions for our participants and may have contributed to our results. If dialect is a form of integration between French and Arabic, then its use should provide a common ground, diminishing differences between the two standard conditions. Any replication should address this recommendation.

\section{References}

Benet-Martinez, V., Leu, J., Lee, F., \& Morris, M.W. (2002). Negotiating biculturalism: Cultural frame switching in biculturals with oppositional vs. compatible cultural identities. Fournal of Cross-Cultural Psychology, 33 (5), 492-516.

Benet-Martinez, V. \& Haritatos, J. ( 2005). Bicultural identity components and psychosocial antecedents. Journal of Personality, 73 (4), 1015-1049.

Berlin, B. \& Kay, P. (1969). Basic color terms: their universality and evolution. Berkeley: University of California Press.

Bond, M.H. \& Yang, K.S. (1982). Ethnic affirmation versus cross-cultural accommodation: The variable impact of questionnaire language on Chinese bilinguals from Hong Kong. Journal of Cross-Cultural Psychology, 13, 169-185.

Boski, P. (2008). Five meanings of integration in acculturation psychology. International fournal of Intercultural Relations, 32 (2), 142-153.

Boski, P. (2012). Psychology of a culture: Humanism and social ineffectiveness embedded in Polish ways of life. In W. Friedlemeier (Ed.), Online readings in psychology and culture. [http://scholarworks.gvsu.edu/orpc/].

Dziubiński, A. (1995). Historia Tunezji [History of Tunisia]. Wrocław: Ossolineum. Hadith, Sahih Al-Bukhari, Postprint available free at: http://www.searchtruth.com/ hadith_books.php

Heider, E.R. (1972). Universals in color naming and memory. Journal of Experimental Psychology, 93, 10-20. 
Hoffman, C., Lau, I., \& Johnson, D.R. (1986). The linguistic relativity of person cognition: An English-Chinnese comparition. Fournal of Personality and Social Psychology, 51 (6), 1097-1105.

Hong, Y., Morris, M.W., Chiu, C., \& Benet-Martinez, V. (2000). Multicultural minds: A dynamic constructivist approach to culture and cognition. American Psychologist, 55 (7), 709-720.

Jarosz., Z. (Ed.) (1997). Konstytucja V Republiki Francuskiej [Constitution of the French Fifth Republic]. Warszawa: Wydawnictwa Prawnicze PWN.

Kemmelmeier, M. \& Cheng, B.-Y. (2004). Language and self construal priming; A replication and extension in a Hong Kong sample. Journal of Cross-Cultural Psychology, 35, 705-712.

Koran (1986). [Selected verses in translation by J. Bielawski]. Warszawa: Państwowy Instytut Wydawniczy.

LaFromboise, T., Coleman, H.L., \& Gerton, J. (1993), Psychological impact of biculturalism: Evidence and theory. Psychological Bulletin, 114 (3), 395-412.

Machut-Mendecka, E. (2003). Normy obyczajowe we wspótczesnej kulturze arabskomuzutmańskiej. Oblicza wspótczesnego islamu [Moral norms in the contemporary Arab-Muslim culture. The faces of contemporary Islam]. Warszawa: Academica.

Osińska, A. (2007). Przełązanie tożsamościowe u polsko-amerykańskiej młodzieży dwukulturowej [Identity switching in the Polish-American bicultural young people]. SWPS, Warszawa (unpublished master's thesis).

Ralston, D.A., Cunni, V.M.K., \& Gustafson, D.J. (1995). Cultural accommodation:The effect of language on the responses of bilingual Hong Kong Chinese Managers. fournal of Cross-Cultural Psychology, 26, 714-727.

Rekłajtis, E. ( 1976). Maghreb wspótczesny z badań nad kontaktem $i$ wspótrozwojem kultur [Contemporary Maghreb from research on contact and co-development cultures]. Warszawa: PWN.

Roberson, D., Davies, I., \& Davidoff, J. (2000). Color categories are not universal: Replications and new evidence from a stone-age culture. Fournal of Experimental Psychology: General, 129 (3), 369-398.

Roberson, D., Davidoff, J., Davies, I.R.L., \& Shapiro, L.R. (2004). The development of color categories in two languages: A longitudinal study. Fournal of Experimental Psychology: General, 133 (4), 554-571.

Rosch, E. (1977). Linguistic relativity. In P.N. Johnson \& P.C. Wason (Eds.), Thinking. Readings in cognitive science (pp. 501-519). Cambridge: Cambridge University Press.

Ross, M., Xun, W.Q.E., \& Wilson, A.E. (2002). Language and the bicultural self. Personality and Social Psychology Bulletin, 28, 1040-1050.

Ryan, R.M., Deci, E.L. (2000). Self-determination theory and the facilitation of intrinsic motivation, social development, and well-being. American Psychologist, 55 (1), 68-78 
Sapir, E. (1978). Culture, language and personality. Warsaw: National Institute of Publishing.

Schwartz, S.H. (1992). Universals in the content and structure of values: Theory and empirical tests in 20 countries. In M. Zanna (Ed.), Advances in experimental social psychology. Vol. 25 (pp. 1-65). New York: Academic Press.

Schwartz, S.H. (1996). Value priorities and behavior. In C. Seligman, J.M. Olson, M.P. Zanna (Eds.), The psychology of values. The Ontario Symposium. Vol. 8 (pp. 1-24). Mahwah, NJ: Lawrence Erlbaum.

Schwartz, S.H., Lehmann, A., \& Roccas, S. (1999). Multimethod probes of basic human values. In J. Adamopoulos \& Y. Kashima (Eds.), Social psychology and cultural context (pp. 107-123). Thousand Oask: Sage.

Schwartz, S.H. (2004). Mapping and interpreting cultural differences around the world. In H. Vinken, J. Soeters, \& P. Ester (Eds.), Comparing cultures. Dimensions of culture in a comparative perspective (pp. 43-73). Leiden: Brill.

Wang, Q., Shao, Y., \& Li, Y.J., (2010). My way or mom's way? The bilingual and bicultural self in Hong Kong Chinese children and adolescents. Child Development, 81 (2), 555-567.

Wiechecki, J. (1973). Tunezja [Tunisia]. Warszawa: Centrum Informacji Naukowej, Technicznej i Ekonomicznej.

Wierzbicka, A. (1994). Emotion, language and 'cultural scripts'. In S. Kitayama, H.R. Markus (Eds.), Emotion and culture (pp. 133-196). Washington: APA.

Wierzbicka, A. (1999a). Jezyk - umyst - kultura [Language - mind - culture]. Warszawa: PWN.

Wierzbicka, A. (1999b). Emotions cross languages and cultures. Cambridge: Cambridge University Press.

Wierzbicka, A. (2010). Experience, evidence, \& sense. The hidden cultural legacy of English. Oxford: Oxford University Press.

Winczo, M. (1994). Dwa kody - dwa światy? Czyli o tym, co może wynikać z odmiennej genezy kodów: percepcyjno-wyobrażeniowego i słowno-twierdzeniowego. [Two codes - two realities? Consequences of differences in the origin of perceptual and verbal codes]. In M. Jarymowicz (Ed.), Poza egocentryczna perspektywa widzenia siebie $i$ innych [Beyond the egocentric perspective of seeing themselves and others] (pp. 131-154). Warszawa: Wydawnictwo IP PAN. 